\title{
El historiador del ludismo, Edward P. Thompson, y la "Economía moral de la multitud"1
}

The historiographer of Luddism, E.P. Thompson, and the "Moral economy of the crowd"

Clément Homs 2

Investigador independiente, Francia clementhoms@orange.fr

\section{Resumen}

El presente artículo nos da a conocer un nuevo enfoque desde la teoría crítica marxista, surgida desde nueva crítica del valor (Moishe Postone, Robert Kurz), enfatizando desde este enfoque una interpretación de las tesis historiográficas sobre los movimientos populares premodernos de Europa, por parte del célebre historiador E.P. Thompson, poniéndolo en diálogo con otras corrientes historiográficas y autores, principalmente de la línea francesa tal como lo son Jacques Le Goff, Jean Nicolas, Georges Lefebvre, así como también comparando descripciones de los movimientos sociales y sujetos de aquella transición histórica con autores tales como Cynthia Bouton, para analizar y exponer de manera más detalladas a los sujetos populares premodernos que caracterizaron parte de Francia del siglo XVII-XVIII, al igual que los preceptos modernos de economistas políticos clásicos (Adam Smith) en debate con las teorías marxistas de corriente situacionista (Ivan Ilich y Guy Debord), dando a entender el panorama social, político y económico de las resistencias al proceso de invención economicista propio del mercantilismo moderno.

Palabras Clave: Critica del valor; Ludismo; Historiografía Marxista; Economicismo Moderno.

\footnotetext{
${ }^{1}$ Artículo publicado el 23 de mayo del 2007 en la página oficial de la Wertkritik francesa, disponible en http://www.palim-psao.fr/article-10535780.html. Traducción de Emilio Guzmán Lagreze.

2 Teórico y militante francés, miembro de la Révue Jaggernaut, "Crise et critique de la société capitaliste patriarcale". Miembro de las ediciones Crise et Critique de la crítica del valor francesa, además gestiona el sitio web http://www.palim-psao.fr donde se publica gran parte del material de la Wertkritik francesa.
} 


\section{Abstract}

This article give us a new approach from the marxist critical theory, which comes from the new value criticism (Moishe Postone, Robert Kurz), emphasizing with this focus into a new interpretation of the historiographical thesis about the European pre-modern and popular movements done by the well known historiographer E.P. Thompson, putting this lecture in relationship with different historiographical tendencies and authors, mainly from the French Historiographical Current as Jacques Le Goff, Jean Nicolas, Georges Lefebvre, and also by comparing the descriptions of the social movements and subjects from that historical transition with authors as Cynthia Bouton, to analyse and present more deeply the popular subjects from the pre modern industrial revolution times that characterised the France of the XVIIXVIII centuries. Also this text compare the modern concepts of the classical political economists (Adam Smith) into a debate with the marxists lectures raised in the situationist movement (Ivan Ilich, Guy Debord), allowing us to analyse the social, political and economic panorama of resistances to the invention of the economicist process proper to the modern mercantilism.

Keywords: Value criticism; Luddism; Marxist Historiography; Modern Economicism.

\section{Introducción}

El gran historiador británico Edward P. Thompson es por lo general más citado en referencia a su magnífica historia del movimiento ludita, que por su concepto de "economía moral de la multitud", cosa que es pertinente remarcar para llevar de buena manera las primeras formas de oposición a la "invención de la economía política burguesa", llevada a cabo durante los siglos XVII y XVIII. En efecto, dicho historiador en oposición a las corrientes historiográficas (principalmente marxistas) que propugnaban una visión espasmódica de la historia popular, ha querido demostrar durante toda su vida que las acciones populares designadas con conceptos tales como "revueltas", "rumores" "ruidos" o "emociones" en las fuentes judiciales, no podrían ser reducidas a reacciones instintivas provocadas por el hambre de las clases bajas.

Para E.P. Thompson, las revueltas rurales son, tanto vector de una política latente, de una cultura y de una moral ordinaria (una "common decency", en el sentido de Michéa (2002:29)) como fruto de un buen sentido de la orientación de la gente más pobre. El objetivo de Thompson (2003) a través de su concepto de "economía moral de la multitud", es un poco similar a aquel de rescatar a los luditas de "la enorme condescendencia de la posteridad", que se encuentra en tantas oportunidades en la historiografía económica obsesionada con la construcción de 
indicadores científicos de crecimiento económico, más que de una historiografía obrera preocupada por mostrar el auge y la gloria de los "verdaderos" (más que falsos) representantes de la clase obrera. En efecto, el historiador marxista no veía en las revueltas alimentarias más que formas arcaicas de protesta y de reivindicaciones a años luz de las estructuras revolucionarias validadas por partidos comunistas mundiales al orden de la Unión Soviética Totalitaria y su proyecto de "modernización de recuperación" (Kurz, 2016), es decir, de constitución de la forma de vida social mediada por el trabajo abstracto, el valor y el dinero, mediaciones por tanto, intrínsecamente capitalistas, como lo ha mostrado Moishe Postone (2006).

Las tesis aventuradas e iconoclastas de E.P. Thompson toman desconfianza respecto a las grandes proposiciones que pesaban en los debates históricos durante la Guerra Fría; ellas son, por tanto, inseparables de su reflexión militante, marxista y heterodoxa, llena de polémicas en el seno de la izquierda inglesa de fines de los años 1950.

\section{La "economía moral de la multitud" contra la emergencia de la realidad y del imaginario económico}

Es más, E.P Thompson intenta demostrar que aquello que él llama puede ser impropiamente la vieja "economía moral de subsistencia" y la "economía moral de la multitud" no han desaparecido a finales del siglo XVII, sino que han perdurado, al menos en parte, hasta los últimos años del siglo XVIII. Ello quiere decir, desde la crítica del valor (Wertkritik), que dicho movimiento social perdura hasta la victoria del proyecto metafísico de la nueva economía política del libre-mercado, aquel de la economía política burguesa (Latouche, 2005; Kurz, 2016; Parker, 1996). Encontramos ahí la tesis de Jacques Le Goff (2008) sobre la no pertinencia de la idea de una ruptura fundamental en las relaciones sociales fundamentales en el Renacimiento, y la existencia, por el contrario, de una larga Edad Media, que perdura hasta el siglo XVIII junto con su imaginario económico. Pero también las relaciones socioeconómicas (por tanto el propio capitalismo), estando ajenas a la Edad Media, y las relaciones sociales se encontrarían en dicho período histórico subsumidas e incrustadas en relaciones político-religiosas que siguen siendo dominantes durante aquel período. En aquel momento de báscula, es decir, de la constitución de la forma de vida social capitalista, mediada por el trabajo, la mercancía, el movimiento autómata del valor y del dinero, Thompson (2003) resulta ser el historiador de la confrontación, a veces violenta de los siglos XVII y XVIII, de esos dos mundos sociales muy diferentes.

Edward P. Thompson (2003) comienza por exponer el reemplazo progresivo y desigual siguiendo las regiones de la antigua "economía" (por diversas razones que no expondremos aquí, es necesario ser prudente en el uso de ciertos 
anacronismos de este término) todavía encastrada dentro de la sociedad, por las nuevas tendencias de la autonomización de lo económico dentro de la invención económica burguesa en el transcurso del siglo XVIII. En efecto, Adam Smith, en su libro "La riqueza de las naciones" (1776), desarrolla la matriz de las nuevas leyes de la esfera económica, desde entonces, autonomizada por esta normatividad dominante de sus "leyes" de una potencia auto realizable. Pero el proyecto metafísico de Smith constituye menos un modelo que un antimodelo. En efecto, su obra está atravesada por una tensión interna, opuesta a la política paternalista de "subsistencia" de la dinastía inglesa de los Tudor, que ofrecían, cuando había necesidad, los stocks de trigo a la población 3 .

La tesis de la "mano invisible" de Smith está directamente dirigida contra el intervencionismo paternalista del Estado real, que también había sabido cada vez más monetarizar su punción fiscal desde el siglo XVI, autonomizándose de su última dependencia a las relaciones sociales feudales (Smith, 2011). Cuando a fines del siglo XVIII declinan los métodos paternalistas tradicionales de gobierno, bajo la influencia de las tesis Smithianas, la "economía moral de la multitud" toma el lugar vacío dejado por los reflujos del soberanismo. En una esfera económica que detenta sus propias leyes, la abstracción del mercado no está mejor regulada que cuando se le deja regular al mercado mismo, tal como decía Smith. Así, para E. P. Thompson, el proyecto de Adam Smith es el de una "desmoralización" de la esfera de las actividades, satisfaciendo las necesidades, mediante la extracción de la economía de la moral de la sociabilidad ordinaria, pero también de la sociabilidad determinada por las relaciones de dominación, y en la ocurrencia de la relación social de sujeción al poder real. Desde ahí la nueva economía política está libre de imperativos morales inoportunos a su propio auto-crecimiento. A partir de ahora "[...] es un dominio de los asuntos humanos, aislables unos de otros, en donde la moral y los modos de socialización tradicionales son inútiles, e incluso dañinos [...] en este dominio y siguiendo sus intereses egoístas, los hombres trabajan sin saber del bien común" (Dupuy, 1992: 76). Adam Smith logra aquí desbloquear el despliegue de la producción de representaciones irreales. La economía se emancipa de la moral ligada a las antiguas relaciones sociales y se desincrusta de la sociabilidad intersubjetiva (Debord, 1995: 51).

Liberada de la moralidad originaria, verdadera condición de posibilidad de la generalización del intercambio a los ojos de Thompson, el mercado abstracto de los intercambios objetivos aparece en su auto crecimiento, siempre más ilimitado a medida que destruye los antiguos vínculos sociales. Después de haber ganado

3 Esta práctica de la realeza del 'evergetismo' alimentario aparece desde el antiguo Egipto, para devenir un verdadero instrumento político dentro de las realezas helenísticas de los herederos de los Diádocos. 
bastante inercia y fuerza, constituye la forma de vida social capitalista que integra también la forma estatal que le corresponde.

\section{La historia popular de la resistencia a la sociedad economicista.}

E. P. Thompson describe las primeras luchas populares al momento del nacimiento del Leviatán tecno-económico Smithiano. Desde su origen, el pueblo siente que no tiene nada que esperar de la emergencia de la economía, que no es más que el lado concreto y directamente visible de las relaciones sociales capitalistas mediadas por el trabajo abstracto. Este reacciona sintiéndose afectado y saca de hecho su legitimidad del modelo paternalista de los Tudor. En Francia, la economía moral de la multitud que se ilustra en la 'Guerra de las harinas' de 1775, se opone a la política fisiocrática del gobierno de Turgot, verdadero clon francés de Adam Smith4. El primer elemento de la puesta en lugar del libre cambio es en efecto la desvinculación del rey de su paternalismo 'evergeta' tradicional (Kaplan, 1986): a partir de ahora él acepta que los propietarios de granos tengan un control absoluto5 ${ }^{5}$ sobre la venta de su bien.

Son numerosos los sujetos que durante el siglo XVIII ven al intermediario comercial como un intruso. Los mercaderes se desplazan cada vez más buscando los mejores precios, se rehúsan a vender a los pobres que solo compran en pequeñas cantidades. Los viejos mercados locales que son siempre mayoritarios respecto a los intercambios mercantiles objetivados, por su propio proceso de mercantilización se ven en declive (Latouche,2005). Es también el contexto de invención de la figura del maestro panadero6. La hostilidad es entonces cierta contra los mercaderes. Toda exportación extra local o regional, sobre todo en el período de escasez, supone un levantamiento de los escudos. La sensibilidad moral de los amotinados no se limita a las regiones de exportaciones en ultramar, ya que las regiones secundarias de exportación son igualmente tocadas por estos amotinados antieconómicos. Estos

4 En Francia, la primera tentativa de introducción del libre-intercambio data de 1763/1764 y 1771. La tercera tentativa será aquella de Turgot en 1774, dándole inmediatamente lugar a la 'Guerra de las harinas'.

5 Prefiguración de la "propiedad exclusiva" del Código civil de 1801.

${ }_{6}$ Nota del autor: En efecto, antiguamente a cada hogar llevaba molido su propio grano en el molino del meunier. La figura del meunier era hasta entonces central en el imaginario popular. Pero desde entonces que la economía toma su autonomía a través de la extensión de la esfera de los productos intercambiados por intermediarios, el meunier se transformaba cada vez más en mercader: hacían directamente el molde para los panaderos y tenían entonces poco tiempo para los pequeños clientes que vivían de la agricultura de subsistencia. Desde finales del siglo XVIII en Inglaterra, mucha gente tuvo, sin embargo, el hábito "par la force des choses" (Frase utilizada por el autor Bernard Charbonneau, teórico y escritor francés, cercano a Jacques Ellul, los cuales son referenciados de manera constante por parte de los teóricos de la Nueva crítica del valor francesa, por sus perspectivas anti industrializadoras y críticas respecto a la sociedad moderna) de comprar su pan directamente donde el panadero. 
revoltosos participan de la "mentalidad revolucionaria", descrita por Georges Lefebvre (1986) como una mezcla explosiva de inquietudes y de esperanzas alimentada por la circulación de rumores. La composición profesional de esas multitudes es aquella de las "clases bajas" que no tienen ningún centavo, posaderos, tejedores, vendedores domésticos, vendedores mineros, la mano de obra agrícola, a veces los propietarios de medianas tierras (durante la "guerra de las harinas"), y muy a menudo las mujeres. Estas revueltas populares consisten generalmente en el impedimento de la circulación de granos (sobre las vías fluviales o terrestres) para que no salgan de la región, pero encontramos también prácticas de punción de bolsas, el pillaje de los almacenes y la tasación popular de los granos.

Esos "revoltosos" que relatan por millares los archivos ingleses, que podrían hasta devenir en una verdadera "Guerra de las harinas" como en Francia en 1775, no son formas arcaicas de sublevación, como lo ha pretendido la dogmática historiografía marxista. Esos revoltosos anti-económicos desarrollan, en efecto, modelos de comportamiento tomando sus orígenes hace más de un siglo atrás. Así, si se lo mira de más cerca, en la forma dominante de esos revoltosos, es decir, la 'tasación de los precios', podemos observar en ella siempre un desarrollo muy particular: la multitud toma por asalto el convoy de un negociante o de un proveedor (la nueva clase de intermediarios del intercambio mercantil) y le compra su mercancía, pero haciendo su propio precio calificado de 'precio justo', considerando el del vendedor como 'injusto', y por tanto 'a-moral'7. El proceso clásico de ese tipo de revoltoso es aquel de una primera partida de la multitud del mercado hacia los molinos, luego bifurcándose hacia las granjas que esta visita una a una, comprando los granos a un 'precio justo'.

Los revoltosos pueden disfrazar o ennegrecerse el rostro. Sin embargo, dichos sujetos utilizan un código de conducta hacia las víctimas: no se les roba el grano, se les compra de nuevo a un precio decidido por la multitud. Esta 'honestidad' de los revoltosos se explica por el hecho que ellos deben continuar viviendo al lado de sus víctimas que son a menudo sus vecinos ricos. Parece haber igualmente un código de conducta hacia los otros revoltosos: expanden el grano sobre el suelo permitiendo un 'derecho universal de acceso a la subsistencia' (Bouton, 1993). Cuando el 'monopolista' (tal vocabulario encuentra particularmente su eco en las tesis de Ivan Illich (2003) sobre el 'monopolio radical' que destruye toda posibilidad de autonomía) oculta demasiado bien su reserva de granos de los ojos de la multitud,

\footnotetext{
7 Nota del autor. Ese medio de acción ha sido codificado en Inglaterra en el Book of Orders entre 1580 y 1630, como medida de urgencia de los tiempos de penuria. Ese Book va a quedar por largo tiempo en la memoria popular, incluso si está demasiado lejano. Regularmente circulan diversos panfletos o afiches clavados sobre carteles recordando las buenas maneras a los 'monopolistas' y 'acaparadores' potenciales bajo pena de la sublevación popular. Ello toca particularmente las viejas regiones
} 
esta ataca los molinos y los cierra, destruyendo los equipamientos y esparciendo la harina en los ríos. La multitud no es nunca estúpida, ella está también muy bien informada, ya que sus miembros trabajan en los muelles, en los mercados, en los molinos, en los campos. Ella está entonces mucho más al tanto que la policía, por lo que ahí encuentra sin errores las reservas de granos. Ellos saben muy bien que la única forma de someter a los ricos es retorciéndoles el brazo.

Aquellos revoltosos, nos demuestra Thompson, conocen de la misma manera, a finales del siglo XVIII, una transformación de la naturaleza de la protesta (Nicolas, 2002; Bouton, 1993): se ataca a los símbolos del poder (el Antiguo Régimen y la élite agrícola), así como a los símbolos de la distinción social (bancos de la iglesia, veletas, escudos, etcétera). El historiador Jean Nicolas contabiliza así para lo que es la región de Francia, cerca de 512 revueltas anti señoriales entre 1661 y 1789, y cerca de 1526 revueltas alimentarias relacionadas directamente con las formas de la economía moral de la multitud descrita por E. P. Thompson: de manera más exacta, Nicolas da cuenta de cerca de 564 revueltas contra la carestía; 119 revueltas contra el acaparamiento de los granos y cerca de 707 revueltas contra la salida de los granos en aquel momento histórico (Nicolas, 2002).

Es así que la 'Guerra de las harinas', que ha tenido lugar esencialmente dentro de los 'países de la gran cultura' (la corona de la cuenca parisina, la cual será el próximo granero de trigo de Europa), en donde la emergencia de la realidad económica es la más avanzada, es una verdadera revuelta que ve aparecer un vasto 'Movimiento agrario de envergadura' contra la sociedad Smithianna, superando largamente la simple cuestión de la tasación popular de los granos, la cuestión del poder y la puesta en cuestión de las relaciones socio económicas desde ahora planteadas. Como lo ha escrito Jean Nicolas (2002), “[...] la dimensión política de esos movimientos se encuentra mucho más dentro de la voluntad de una fracción de establecer nuevas reglas en nombre de la comunidad y de sus derechos. [...] Las crisis de las rebeliones son políticas en el sentido en donde ellas tocan los usos y costumbres" (Nicolas, 2002).

La dimensión política no está entonces autonomizada, vale decir 'desincrustada' de la vida social, como dentro de las formas modernas de la esfera política (Ellul, 2004). La política y lo social están todavía ahí indiferenciadas (Crouzet-Pavan, 2001). Es decir, esta 'infra política' tiene su enraizamiento dentro del curso espontáneo de la experiencia social históricamente determinada. Ella toma primero la forma de un trabajo o de una vivencia en común, al seno de esta dimensión social de la esencia del individuo, como lo ha explicado Michel Henry:

manufactureras del Este y del Oeste; la multitud pretendía ahí que, ya que las autoridades rechazaban aplicar las «leyes», debía hacerla por ella misma. 
“[...] Cuando una dificultad surge en la realización de ese trabajo, los actores involucrados se juntan y se ponen de acuerdo. De la confrontación de sus puntos de vista resulta la decisión que les parezca mejor. De ser tomada en común, ella reviste una suerte de legitimidad y es así que todos de someterán a ella. Es en esta situación que se forma la idea democrática, la idea de una comunidad que decide ella misma de su organización y sus fines. En tanto que la idea democrática nace en el plano de la actividad social, una brecha decisiva se produce: esta actividad se desdobla, ella no es más únicamente social sino que política. En lugar de realizarse espontáneamente, ella se interrumpe para devenir objeto de una reflexión. Ello está motivado por la necesidad de integrar una acción particular en un conjunto mucho más vasto y finalmente a la totalidad de las acciones de un grupo. Esta toma en consideración del sistema global de las acciones marca la apertura de un campo nuevo y absolutamente original, aquél de la política - la cual descansará en el conocimiento y no en el hacer. Tal mutación es decisiva, ya que ella concierne a la fenomenología misma de los fenómenos en juego. A la acción real inmersa dentro de la vida se muestra en su pathos el despliegue de una dimensión propiamente política de las representaciones, de las ideas, una ideología - pero antes el medio de luz donde se muestran sus representaciones y sus ideas" (Henry, 2004: 167-168. La traducción es nuestra).

Para dar un ejemplo de esos revoltosos verdaderamente anti economicistas (en el sentido mercantil del término) e infra políticos, en 1775, en la región inglesa cercana de Haverfordwest, los rumores sobre las exportaciones secretas de granos hacia Francia circulan entre las clases populares. Las rutas son inmediatamente bloqueadas por la población para prevenir la exportación fuera de las parroquias. Los carros son interceptados y descargados de las ciudades que atraviesan. Los movimientos de granos por convoyes de noche toman entonces las proporciones propias de operaciones militares. Las amenazas de destrucción de los canales son sucesivas, mientras que las embarcaciones son atacadas en los puertos. Los mineros de Nook Colliery amenazan con bloquear el estuario en un lugar estrecho. Este es un ejemplo entre miles de otros de la indignación moral contra los mercaderes, por lo que los compromisos hacia el mercado exterior interrumpían el aprovisionamiento de la comunidad local. 
La 'economía moral de la multitud' es así la primera forma de resistencia al proyecto metafísico del librecambio propio del proceso de valorización capitalista (sinónimo de los términos 'economía' o 'capitalismo') (Lasch, 2002). Esos revoltosos ya fueron creciendo en sus luchas anti economicistas durante la revuelta: "todos aquellos que no tienen ningún poder sobre su vida y que lo saben" (VV.AA, 2018; Unión Nacional de estudiantes de Francia y Asociación federativa General de los estudiantes de Strasbourg, 1966). Para aquello que resulta ser (hasta el día de hoy) propio de las luchas espectaculares de los partidos políticos de extrema izquierda, de los altermundistas y de los cortejos carnavalescos de sindicalistas enturbados, estos cegados por los beneficios del capitalismo que ellos pretendían (contra viento y marea) superar, no supieron tener en cuenta, como lo dijo Paul Lafargue, "[...]la desmoralización que la burguesía se había impuesto como deber social, los proletarios tenían [entonces] en mente infligir en el trabajo a los capitalistas. Los ingenuos, tomaron en serio las teorías de los economistas y de los moralistas sobre el trabajo y se amarran los riñones para infligir en la práctica a los capitalistas" (Lafargue, 1999: 37).

\section{Bibliografía:}

Bouton, C. (1993): The Flour War: Gender, Class and Community in Late Ancien

Regime France. University Park, PA.Penn State University Press.

Crouzet-Pavan, E. (2001): Enfers et Paradis. L'Italie de Dante et de Giotto. Paris, Albin Michel.

Debord, G. (1995): La sociedad del espectáculo. Buenos Aires, Editorial La Marca.

Dupuy, J. P. (1992): Le Sacrifice et l’Envie. París, Calmann-Lévy.

Dupuy, J. P. (1998): El sacrificio y la envidia. La justicia social y el liberalismo. Barcelona. Gedisa.

Ellul, J. (2004): L’illusion politique. Paris, La Table ronde.

Henry, M. (2004): "Difficile démocratie “, en M. Henry, Phénoménologie de la vie. Tome III, De l'art et du politique. Paris, Puf.

Henry, M. (2011): Fenomenología de la vida. Buenos Aires, Prometeo editorial.

Illich, I. (2003): Oeuvres Completes V.I. París. Fayard. 
Kaplan, S. (1986): Le Pain, le peuple et le Roi. La bataille du libéralisme sous Louis XV. Paris, Librairie Académique Perrin.

Kurz, R. (2016): El colapso de la modernización. Buenos Aires, Editorial Marat.

Lafargue, P. (1999): Le Droit à la paresse. Paris, Mille et une nuits.

Lafargue, P. (1986): El derecho a la pereza. México, Editorial Grijalbo.

Lasch, C. (2002): Le Seul et vrai paradis. Une histoire de l'idéologie du progrès et de ses critiques.Paris. Èditions Climats, Flammarion.

Latouche, S. (2005): L’Invention de l'économie, Paris. Albin Michel.

Le Goff, J. (2008): Una larga edad media. Barcelona. Editorial Paidos.

Lefebvre, G. (1986): El gran pánico de 1789: la Revolución Francesa y los campesinos. Barcelona, Paidós.

Michéa, J. C. (2002): La escuela de la ignorancia y sus condiciones modernas. Madrid, Ediciones Acuarela.

Nicolas, J. (2002): La Rébellion française. Mouvements populaires et conscience sociale, 1661-1789. Paris, Éditions du Seuil.

Parker, G. (1996): The Military Revolution: Military Innovation and the Rise of the West, 1500-1800. Cambridge, Press Syndicate of the University of Cambridge.

Postone, M. (2006): Tiempo trabajo y dominación social. Una reinterpretación de la teoría crítica de Marx. Madrid, Editorial Marcial Pons

Smith, A. (2011): La riqueza de las naciones. Madrid, Alianza Editorial.

Thompson, E. P. (1974): "La economía 'moral' de la multitud en la Inglaterra del siglo XVIII”, Revista de Occidente, 133, 1974, pp. 54-125

Thompson, E. P. (2000): Costumbres en común. Estudios en la cultura popular tradicional. Barcelona, Crítica.

Unión Nacional de estudiantes de Francia y Asociación federativa General de los estudiantes de Strasbourg (1966): De la misère en milieu étudiant. Considérée sous ses 
aspects économique, politique, psychologique, sexuel et notamment intellectuel et de quelques moyens pour y remédier.

VV.AA. (2018): De la miseria en el medio estudiantil y otros documentos. Logroño, Editorial Pepitas de Calabaza.

Fecha de recepción: 29 de abril de 2020

Fecha de aceptación: 20 de junio de 2020 